\title{
Relationship Between Preconception Care and Pregnancy Planning Status with Folic Acid and Smoking: A Cross- Sectional Study
}

\author{
Gebelik Öncesi Bakım Alma ve Gebeliklerin Planlı Olma Durumunun Folik \\ Asit ve Sigara İle İlişkisi: Kesitsel Bir Araştırma
}

\author{
Ceyhun Yurtsever ${ }^{* 1}$, Turan Set ${ }^{1}$
}

\begin{abstract}
Introduction: In this study, it was aimed to evaluate preconception counseling and pregnancy planning status and to determine the relationship between these status and knowledge about folic acid (FA), use of FA and smoke exposure in pregnant women. Methods: This study was carried out as a cross-sectional study between January-April 2015 among women who applied to Karadeniz Technical University Medical Faculty for pregnancy follow-up (n=199). Participants' demographic characteristics, preconception counseling and pregnancy planning status, knowledge and use of FA, smoking and passive smoking were evaluated by applying a questionnaire face to face interview method. Descriptive statistics, Student $t$ test, Mann-Whitney U test and Chi square test were performed. Statistical significance level was taken as $\mathrm{p}<0,05$. Results: The mean age of participants was $30.2 \pm 5.8$ years. Twenty-six percent of the participants had consulted by any doctor for preconception care. The proportion of women who indicated that they planned current pregnancy was $63.8 \%$. While rate of those who stated that they use regular FA was $\% 62,8$, ten percent of them started to use it before conception. The rate of those who continued to smoke during pregnancy was $6,5 \%$ and $32 \%$ of the participants were exposed to smoke. In pregnants with preconception counseling; rate of pregnancy planning, using FA before pregnancy and knowing that FA prevented birth defects were higher $(\mathrm{p}<0,05)$. There was no statistically significant relationship between demographic characteristics, regular FA use and smoking exposure and preconception counseling ( $p>0,05)$. Conclusion: Preconception care services, a very important opportunity in terms of improving the health of women and possible children, have been found to be inadequate in our study. All health workers who serve women in the reproductive age should be encouraged to have preconception counseling.
\end{abstract}

Key words: Folic acid, planned pregnancy, preconception care, primary care, smoke

\section{ÖZET}

Giriş: Bu çalışmada, gebelerin, gebelik öncesi danışmanlık alma ve gebeliklerinin planlı olma durumunun; folik asit (FA) hakkında bilgi düzeyi, FA kullanımı ve sigara dumanı maruziyeti ile ilişkisinin değerlendirilmesi amaçlanmıştır. Yöntem: Bu çalışma, Karadeniz Teknik Üniversitesi Tıp Fakültesine, gebelik takibi amacıyla başvuran kadınlar arasında, Ocak-Nisan 2015 tarihleri arasında kesitsel bir araștırma olarak yürütülmüştür (n=199). Katılımcıların demografik özellikleri, gebelik öncesi danışmanlık alma durumu, gebeliğinin planlı olup olmadığı, FA hakkında bilgi düzeyi ve kullanımı, sigara kullanımı ve pasif içicilik durumu, yüz yüze görüşme yöntemiyle bir anket formu uygulanarak değerlendirilmiștir. Tanımlayıcı istatistikler, Student $t$ testi, Mann-Whitney $\mathrm{U}$ testi ve Ki kare testi yapıldı. İstatistiksel anlamlılık düzeyi p $<0,05$ olarak alınmıştır. Bulgular: Katılımcıların yaş ortalaması 30,2 $\pm 5,8$ yıldı. Gebelik öncesi bakım için, herhangi bir doktordan danıșmanlık alanların oranı \%26,1'di. Mevcut gebeliğini planladığını belirten kadınların oranı \%63,8'di. Düzenli FA kullandığını belirtenlerin oranı \%62,8 iken, bunların sadece \%9,9'u gebelik öncesinde kullanmaya başlanmıştı. Gebeliği süresince sigara kullanmaya devam edenlerin oranı \%6,5 iken, katılımcıların \%31,7'si sigara dumanına maruz kaldığını belirtmiştir. Gebelik öncesi danışmanlık alanlarda; gebeliklerini planlama, gebelik öncesi FA kullanmaya başlama ve FA'nın doğumsal anomalileri önlediğini bilme oranı daha yüksek bulunmuştur ( $<<0,05$ ). Demografik özellikler, düzenli FA kullanımı ve sigara maruziyeti ile gebelik öncesi danışmanlık alma arasında istatistiksel anlamlı ilişki saptanmamıştır (p>0,05). Sonuç: Çalışmamızda, kadın ve olası çocuklarının sağlı̆̆ının geliştirilmesi açısından çok önemli bir firsat olan gebelik öncesi bakım hizmetlerinin yetersiz olduğu görülmüştür. Üreme çağındaki kadınlara hizmet eden bütün sağlık çalışanları, gebelik öncesi danışmanlık konusunda bilinçlendirilmeli ve cesaretlendirilmelidir.

Anahtar kelimeler: Birinci basamak, folik asit, gebelik öncesi bakım, planlı gebelik, sigara

Received / Geliş tarihi: 03.11.2017, Accepted / Kabul tarihi: 25.12.2017

${ }^{1}$ KTÜ Aile Hekimliği Ana Bilim Dalı

*Address for Correspondence/Yazışma Adresi: Ceyhun Yurtsever. KTÜ Aile Hekimliği Ana Bilim Dalı.TrabzonTÜRKIYE, E-mail: ceyhunyurtsever@hotmail.com

Yursever C, Set T. Gebelik Öncesi Bakım Alma ve Gebeliklerin Planlı Olma Durumunun Folik Asit ve Sigara İle İlişkisi: Kesitsel Bir Araştırma.TJFMPC, 2018;12(1): 43-48. DOI: 10.21763/tjfmpc.399914 


\section{GíRIŞ}

Gebelik öncesi bakım; bir kadının sağlığı veya gebelik sonuçlarına yönelik biyomedikal, davranışsal ve sosyal riskleri tanımlamayı ve değiştirmeyi amaçlayan, maksimum etki için bunun gebelik öncesi ya da erken gebelikte uygulanması gerekliliğini vurgulayan, bir dizi önleme ve yönetim stratejileridir. ${ }^{1-3}$

ABD'de yapılan çalışmalarda, gebelik öncesi bakım alma oranının \%32 olduğu gösterilmiştir., ${ }^{4,5}$ Birçok ülkede, gebelik öncesi bakım, doğum öncesi ve gebelik kılavuzlarında yer alsa da, tanımlanmış risk faktörleri olmayan kadınlara gebelik öncesi bakım verilmesi ihmal edilmiştir. ${ }^{6,7}$ Ülkemizde de benzer şekilde gebelik öncesi bakım hizmetleri, nitelik ve nicelik bakımından beklenenin altında kalmıştır. ${ }^{8}$

Gebelik öncesi bakım, istenmeyen gebeliklerin önlenmesi için en önemli fursattır. ${ }^{9}$ Planlanmış gebeliklerin, daha iyi sağlık sonuçlarıyla ilişkili olduğu açıktır. ${ }^{10}$ Plansız bir gebelikte, kadın gebe kaldığını anlayıp ilk prenatal kontrolüne gelinceye dek geçen sürede fetus, organogenez sürecini çoktan tamamlamakta ve ilk doğum öncesi kontrol, perinatal risk faktörlerini gidermek için geç kalmaktadır. ${ }^{11,12}$

Gebelik öncesi bakım, ilk olarak hekimin hastalarına gebelik niyetlerini sorması ve üreme yaşam planı oluşturulmasını teşvik etmesiyle başlar. Gebelik planlanmıyorsa hekim, uygun kontraseptif yöntemin uygulandığından emin olmalıdır. Gebe kalmak isteyenler için ise risk değerlendirilmesi yapılmalı ve buna uygun danışmanlık verilmelidir. ${ }^{13,14}$

Gebelik öncesi bakım; yaşam tarzı faktörlerinin kontrol edilmesi (kilo kontrolü, aktif veya pasif sigara içiciliği konusunda danışmanlık gibi), annede önceden var olan tıbbi bozuklukların yönetimi, kullanılan ilaçların incelenmesi, enfeksiyonların taranması ve belirtilen aşıların sağlanması, folik asit (FA) takviyesini içeren beslenme düzenlemesi, genetik hastalıklar için tarama ve önceki gebelik komplikasyonlarının gözden geçirilmesi gibi bir dizi müdahaleyi içerir., ${ }^{2,15}$

Nöral tüp hasarlarını önlemek amacıyla, günlük 0,4 mg FA takviyesinin konsepsiyon öncesi başlanması ve gebeliğin 3. ayına kadar sürdürülmesi önerilmektedir. ${ }^{16,17}$

Annenin, aktif ya da pasif sigara dumanına maruz kalmasının, intrauterin büyüme geriliği, prematürite, düşük doğum ağırlığı, konjenital malformasyonlar ve ani bebek ölümü sendromuna yol açabileceği gösterilmiştir. ${ }^{18}$ Bundan dolayı, sigara dumanı maruziyetinin ortadan kaldırılması, gebelik öncesi bakım açısından büyük önem taşımaktadır.

$\mathrm{Bu}$ çalışmada gebelerin, gebelik öncesi danışmanlık alma ve gebeliklerinin planlı olma durumunun; FA hakkında bilgi düzeyi, FA kullanımı ve sigara dumanı maruziyeti ile ilişkisinin değerlendirilmesi amaçlanmıştır.

\section{YÖNTEM}

$\mathrm{Bu}$ çalışma, Karadeniz Teknik Üniversitesi Tıp Fakültesinde Ocak-Nisan 2015 tarihleri arasında kesitsel bir araştırma olarak yürütülmüştür.

Çalışmaya, kadın hastalıkları ve doğum polikliniğine gebelik takibi nedeniyle başvuran 18 yaş ve üstü gönüllü kadınlar dahil edilmiştir. Katılımcılara demografik özelliklerini, gebelik öncesi danışmanlık alma durumunu, gebeliğin planlı olup olmadığını, FA hakkında bilgi düzeyini ve kullanımını, sigara kullanımı ve pasif içicilik durumunu sorgulayan bir anket yüz yüze görüşme yöntemiyle uygulandı. Toplam 199 katılımcının verileri analiz edilmiştir.

Veriler, bilgisayar ortamında SPSS istatistik paket programı kullanılarak analiz edilmiştir. Tanımlayıcı istatistikler yapılmıştır. Numerik değişkenlerin normal dağılımı Kolmogorov Smirnov $\mathrm{Z}$ testi ile değerlendirildi. Numerik bağımsız değişkenler için, ikili karşılaştırmalarda normal dağılıma uyanlarda Student t testi, uymayanlarda Mann-Whitney U testi yapıldı. Kategorik değişkenlerin karşılaştırmasında Ki kare testi kullanıldı. İstatistiksel anlamlılık düzeyi $\mathrm{p}<0,05$ olarak alınmıştır.

\section{BULGULAR}

Katılımcıların yaş ortalaması $30,2 \pm 5,8$ yıldı. Toplam gebelik sayısı ortancası 3 (min:1, max:8), yaşayan çocuk sayısı ortancası 1 (min:0, max:6) idi. Gebe kalmadan önce prekonsepsiyonel bakım için herhangi bir doktordan danışmanlık alanların oranı $\% 26,1$ 'di (n=52). Gebeliğini planladığını belirten katılımcıların oranı \%63,8'di (n=127). Düzenli FA kullandığını belirtenlerin oranı $\% 62,8(n=125)$ iken, bunların sadece $\% 9,9$ 'u $(\mathrm{n}=12)$ gebelik öncesinde kullanmaya başladığını bildirmiştir. FA'nın doğumsal anomalileri önlemesi hakkında bilgi sahibi olanların oranı \%43,2'ydi $(n=86)$. Gebe kalmadan önce katılımciların \%14,6's1 $(\mathrm{n}=29)$ sigara kullandığını belirtmişlerdir. Bunların 44,8'i (n=13) gebeliği süresince sigara kullanmaya devam ederken, \%55,2'si $(n=16)$ gebelik dolayısıyla sigara kullanmayı bırakmıştır. Katılımcıların \%31,7'si $(n=63)$ sigara dumanına maruz kaldığını belirtmişlerdir.

Gebelik öncesi bakım alanlar arasında almayanlara göre planlı gebelik oranı istatistiksel olarak anlamlı derecede yüksek bulunmuştur $(\mathrm{p}<0,001$; Tablo 1).

Yaşı daha büyük $(\mathrm{p}<0,001)$, toplam gebelik sayısı $(p<0,001)$ ve yaşayan çocuk sayısı daha fazla olan $(p<0,001)$, eğitim durumu düşük $(p=0,009)$, çalışmayan $(\mathrm{p}=0,040)$ ve kırsal kesimde yaşayan 
$(\mathrm{p}=0,009)$ katılımc1larda gebeliklerinin planlı olma oranı istatistiksel yönden anlamlı olarak daha düşükken, gebelik öncesi bakım alma açısından istatistiksel olarak anlamlı bir fark bulunamamıştır (s1rasiyla; $\mathrm{p}=0,694, \mathrm{p}=0,683, \mathrm{p}=0,275, \mathrm{p}=0,957$, $\mathrm{p}=0,186, \mathrm{p}=0,833$; Tablo 2).

\begin{tabular}{|l|l|l|}
\hline \multicolumn{2}{|l|}{ Tablo 1. Gebelik öncesi bakım alıp almama durumuna göre gebeliklerin planlı olma durumu } \\
\hline & Planlı gebelikler n (\%) & Plansız gebelikler n (\%) \\
\hline Gebelik öncesi bakım alanlar & $46(88,5)$ & $6(11,5)$ \\
Gebelik öncesi bakım almayanlar & $81(55,1)$ & $66(44,9)$ \\
Toplam & $127(63,8)$ & $72(36,2)$ \\
\hline
\end{tabular}

$\mathrm{p}<0,001$ (Ki kare testi; $\left.X^{2}: 18,513\right)$

\begin{tabular}{|c|c|c|c|c|c|c|}
\hline & $\begin{array}{l}\text { Planlı } \\
\text { gebelikler }\end{array}$ & $\begin{array}{l}\text { Plansız } \\
\text { gebelikler }\end{array}$ & $\begin{array}{l}* \\
Z^{* *}, X^{2 * * * *} \\
(p \text { değeri) }\end{array}$ & $\begin{array}{l}\text { Gebelik } \\
\text { öncesi } \\
\text { bakım } \\
\text { alanlar }\end{array}$ & $\begin{array}{l}\text { Gebelik } \\
\text { öncesi bakım } \\
\text { almayanlar }\end{array}$ & $\begin{array}{l}*, \\
\mathrm{Z}^{* *}, \mathrm{X}^{2 * * *} \\
(\mathrm{p} \text { değeri) }\end{array}$ \\
\hline Yaş, ortalama \pm SS & $29 \pm 5,5$ & $32,4 \pm 5,8$ & $\begin{array}{l}-4,206^{*} \\
(<0,001)\end{array}$ & $29,9 \pm 5,6$ & $30,3 \pm 5,9$ & $\begin{array}{l}-0,394 * \\
(0,694)\end{array}$ \\
\hline $\begin{array}{l}\text { Toplam gebelik sayısl, ortanca } \\
\text { (min-max) }\end{array}$ & $2(1-8)$ & $3(1-8)$ & $\begin{array}{l}-6,583 * * \\
(<0,001)\end{array}$ & $3(1-8)$ & $3(1-8)$ & $\begin{array}{l}-0,409 * * \\
(0,683)\end{array}$ \\
\hline $\begin{array}{l}\text { Yaşayan çocuk sayısı, ortanca } \\
\text { (min-max) }\end{array}$ & $0(0-4)$ & $2(0-6)$ & $\begin{array}{l}-6,795^{* *} \\
(<0,001)\end{array}$ & $1(0-3)$ & $1(0-6)$ & $\begin{array}{l}-1,091 * * \\
(0,275)\end{array}$ \\
\hline $\begin{array}{l}\text { Eğitim durumu, n (\%) } \\
\text { İlköğretim veya altı } \\
\text { Lise } \\
\text { Üniversite veya üstü }\end{array}$ & $\begin{array}{l}53(41,7) \\
43(33,9) \\
31(24,4)\end{array}$ & $\begin{array}{l}46(63,9) \\
17(23,6) \\
9(12,5)\end{array}$ & $\begin{array}{l}9,377 * * * \\
(0,009)\end{array}$ & $\begin{array}{l}25(48,1) \\
16(30,8) \\
11(21,1)\end{array}$ & $\begin{array}{l}74(50,3) \\
44(29,9) \\
29(19,7)\end{array}$ & $\begin{array}{l}0,087 * * * \\
(0,957)\end{array}$ \\
\hline $\begin{array}{l}\text { Çalışma durumu, n (\%) } \\
\text { Çalışan } \\
\text { Çalışmayan }\end{array}$ & $\begin{array}{l}46(36,2) \\
81(63,8)\end{array}$ & $\begin{array}{l}16(22,2) \\
56(77,8)\end{array}$ & $\begin{array}{l}4,198 * * * \\
(0,040)\end{array}$ & $\begin{array}{l}20(38,5) \\
32(61,5)\end{array}$ & $\begin{array}{l}42(28,6) \\
105(71,4)\end{array}$ & $\begin{array}{l}1,752 * * * \\
(0,186)\end{array}$ \\
\hline $\begin{array}{l}\text { Yaşadığı yer, n (\%) } \\
\text { Köy ya da ilçe } \\
\text { Şehir }\end{array}$ & $\begin{array}{l}53(41,7) \\
74(58,3)\end{array}$ & $\begin{array}{l}44(61,1) \\
28(38,9)\end{array}$ & $\begin{array}{l}6,907 * * * \\
(0,009)\end{array}$ & $\begin{array}{l}26(50,0) \\
26(50,0)\end{array}$ & $\begin{array}{l}71(48,3) \\
76(51,7)\end{array}$ & $\begin{array}{l}0,044 * * * \\
(0,833)\end{array}$ \\
\hline
\end{tabular}

*Student $\mathrm{t}$ testi, **Mann-Whitney U testi, ***Ki kare testi

Gebeliği planlı olan katılımcıların, düzenli FA kullanımı $(p=0,005)$ ve FA'nın doğumsal anomalileri önlediğini bilme oranı $(\mathrm{p}=0,003)$ anlamlı olarak daha yüksek olduğu tespit edilmiştir. Gebelik öncesi bakım almak FA'nın konsepsiyon öncesi başlanması oranını $(p<0,001)$ ve FA bilgi düzeyini $(\mathrm{p}=0,001)$ arttırmaktayd. Ancak düzenli FA kullanımı açısından istatistiksel olarak anlamlı fark saptanmamıştır ( $\mathrm{p}=0,075$; Tablo 3 ).

Gebeliği planlı olanlarda, sigara kullanmama oranı anlamlı şekilde daha yüksekken ( $p=0,014)$, gebelik öncesi bakım almayla sigara kullanımı arasında istatistiksel fark tespit edilmemiştir ( $p=0,738)$. Aynı şekilde gebeliğin planlı olma veya gebelik öncesi bakım alma durumuna göre sigara duman maruziyetinde anlamlı bir fark saptanmamıştır (sırasıyla; $p=0,484, p=0,393$; Tablo 4).

\section{TARTIŞMA}

Bu çalışmada, üçüncü basamak bir sağlık kuruluşuna gebelik takibi amacıyla başvuran kadınların, gebelik öncesi danışmanlık alma ve gebeliklerinin planlı olma durumu değerlendirilmiş, FA hakkında bilgi düzeyi, FA kullanımı ve sigara dumanı maruziyeti ile ilişkisi incelenmiştir.

ABD'de yapılan çalışmalarda, gebelik öncesi bakım alma oranının \%32 olduğu, daha genç ve düşük sosyoekonomik statüye sahip olmanın bu oranı azalttığı bildirilmiştir ${ }^{4,5}$. Çalışmamızda ise katılımcıların \%73,9'unun gebelik öncesi bakım almadığı ve incelenen demografik özelliklerin bunu etkilemediği tespit edilmiştir. Bu sonuç, ülkemizde gebelik öncesi bakım hizmetlerinin toplumun bütün kesimleri için bir eksiklik olduğunu göstermektedir. Son yıllarda yapılan çalışmalarda, planlı gebelik oranının Türkiye'de $\% 74,{ }^{19,20}$ ABD de ise yaklaşık $\% 50$ olduğu gösterilmiştir. ${ }^{21,22}$ Bizim çalışmamız, 


\begin{tabular}{|c|c|c|c|c|c|c|}
\hline & $\begin{array}{l}\text { Planlı } \\
\text { gebelikler }\end{array}$ & $\begin{array}{l}\text { Plansız } \\
\text { gebelikler }\end{array}$ & $\begin{array}{l}\mathrm{X}^{2 *} \\
(\mathrm{p} \text { değeri) }\end{array}$ & $\begin{array}{l}\text { Gebelik } \\
\text { öncesi } \\
\text { bakım } \\
\text { alanlar }\end{array}$ & $\begin{array}{l}\text { Gebelik } \\
\text { öncesi bakım } \\
\text { almayanlar }\end{array}$ & $\begin{array}{l}\mathrm{X}^{2 *} \\
(\mathrm{p} \text { değeri) }\end{array}$ \\
\hline $\begin{array}{l}\text { Düzenli FA kullanımı, n (\%) } \\
\text { Evet } \\
\text { Hayır }\end{array}$ & $\begin{array}{l}89(70,1) \\
38(29,9)\end{array}$ & $\begin{array}{l}36(50,0) \\
36(50,0)\end{array}$ & $\begin{array}{l}7,931^{*} \\
(0,005)\end{array}$ & $\begin{array}{l}38(73,1) \\
14(26,9)\end{array}$ & $\begin{array}{l}87(59,2) \\
60(40,8)\end{array}$ & $\begin{array}{l}3,174 * \\
(0,075)\end{array}$ \\
\hline $\begin{array}{l}\text { FA başlanma zamanı, n (\%) } \\
\text { Gebe kalmadan önce } \\
\text { Gebelik öğrenildikten sonra }\end{array}$ & $\begin{array}{l}11(12,6) \\
76(87,4)\end{array}$ & $\begin{array}{l}1(2,9) \\
33(97,1)\end{array}$ & $\begin{array}{l}2,576^{*} \\
(0,108)\end{array}$ & $\begin{array}{l}11(28,9) \\
27(71,1)\end{array}$ & $\begin{array}{l}1(1,2) \\
82(98,8)\end{array}$ & $\begin{array}{l}22,456^{*} \\
(<0,001)\end{array}$ \\
\hline $\begin{array}{l}\text { FA'nın doğumsal anomalileri } \\
\text { önlediğini bilme, n (\%) } \\
\text { Evet } \\
\text { Hayır }\end{array}$ & $\begin{array}{l}65(51,2) \\
62(48,8)\end{array}$ & $\begin{array}{l}21(29,2) \\
51(70,8)\end{array}$ & $\begin{array}{l}9,075^{*} \\
(0,003)\end{array}$ & $\begin{array}{l}19(63,5) \\
33(36,5)\end{array}$ & $\begin{array}{l}53(36,1) \\
94(63,9)\end{array}$ & $\begin{array}{l}11,758^{*} \\
(0,001)\end{array}$ \\
\hline
\end{tabular}

*Ki kare testi

\begin{tabular}{|c|c|c|c|c|c|c|}
\hline & $\begin{array}{l}\text { Planlı } \\
\text { gebelikler }\end{array}$ & $\begin{array}{l}\text { Plansız } \\
\text { gebelikler }\end{array}$ & $\begin{array}{l}\mathrm{X}^{2 *} \\
(\mathrm{p} \\
\text { değeri) }\end{array}$ & $\begin{array}{l}\text { Gebelik } \\
\text { öncesi } \\
\text { bakım } \\
\text { alanlar }\end{array}$ & $\begin{array}{l}\text { Gebelik } \\
\text { öncesi bakım } \\
\text { almayanlar }\end{array}$ & $\begin{array}{l}\mathrm{X}^{2 *} \\
(\mathrm{p} \text { değeri) }\end{array}$ \\
\hline $\begin{array}{l}\text { Sigara kullanımı, n (\%) } \\
\text { Gebelikte devam edenler } \\
\text { Gebelik dolayısıyla bırakanlar } \\
\text { Kullanmayanlar }\end{array}$ & $\begin{array}{l}4(3,1) \\
8(6,3) \\
115(90,6)\end{array}$ & $\begin{array}{l}9(12,5) \\
8(11,1) \\
55(76,4)\end{array}$ & $\begin{array}{l}8,552^{*} \\
(0,014)\end{array}$ & $\begin{array}{l}4(7,7) \\
3(5,8) \\
45(86,5)\end{array}$ & $\begin{array}{l}9(6,1) \\
13(8,8) \\
125(85,1)\end{array}$ & $\begin{array}{l}0,607 * \\
(0,738)\end{array}$ \\
\hline $\begin{array}{l}\text { Sigara dumanına maruziyet, n (\%) } \\
\text { Evet } \\
\text { Hayır }\end{array}$ & $\begin{array}{l}38(29,9) \\
89(70,1)\end{array}$ & $\begin{array}{l}25(34,7) \\
47(65,3)\end{array}$ & $\begin{array}{l}0,490^{*} \\
(0,484)\end{array}$ & $\begin{array}{l}14(26,9) \\
38(73,1)\end{array}$ & $\begin{array}{l}49(33,3) \\
98(66,7)\end{array}$ & $\begin{array}{l}0,730^{*} \\
(0,393)\end{array}$ \\
\hline
\end{tabular}

*Ki kare testi

biraz daha düşük olsa da $(\% 63,8)$ Türkiye verileriyle benzer oranları ortaya koymuştur. Daha büyük yaş, daha fazla gebelik ve çocuk sayısı, düşük eğitim durumu, herhangi bir işte çalışmama ve kırsal kesimde yaşama daha fazla plansız gebelik oranıyla ilişkiliydi. Bu durum Gözükara ve Tezel tarafından 2015 'de yayınlanan ayrı çalışmalarla paralellik göstermektedir. ${ }^{23,24}$ Gebelik planlamasında ortaya çıkan bu sonuç, daha düşük sosyoekonomik statüye sahip bireyler özelinde aile planlaması politikasının gözden geçirilmesi gerekliliğini düşündürmektedir.

Çalışmamızda beklendiği üzere, gebelik öncesi danışmanlık alanlarda gebeliğin planlı olması oranının daha yüksek olduğu görülmüştür. Ülkemizde, gebelik öncesi bakım ve gebeliklerin planlı olması ilişkisini inceleyen benzer herhangi bir çalışmaya rastlanmamıştır. Ancak bu fark 2014'de ABD'de yayınlanan bir çalışmayla örtüşmektedir. ${ }^{5}$ Gebelik öncesi danışmanlık hizmetlerinin geliştirilmesinin plansız gebeliklerin en aza indirgenmesinde büyük öneme sahip olduğu açıtır.

Daha önce Türkiye'de yapılan çalışmalarda, FA'nın doğumsal anomalileri önlediğini bilenlerin oranı yaklaşık $\% 47$ olarak bildirilmiştir. ${ }^{25,26}$ Bizim çalışmamızda ise, gebelerin \%43,2'si FA'nın doğumsal anomalileri önlemesi hakkında bilgi sahibiydi. Gebelik öncesi bakım alanlarda ve planlı gebeliği olanlarda oran daha yüksek bulunmuştur. Yine çalışmamızda üç gebeden ikisinin düzenli FA kullandığı ancak sadece on gebeden birinin konsepsiyon öncesinde kullanmaya başladığ1 görülmüştür. Ülkemizde, FA kullanım oranı değişmekle birlikte gebelik öncesi başlama oranları \%9-14 arasında değişmektedir. ${ }^{25,26} \mathrm{Bu}$ da FA kullanımının yaygınlaşmasına rağmen, gebeliklerin büyük çoğunluğunda geç kalındığını göstermektedir.

Yapılan çalışmalarda, gebelik öncesi bakım alan kadınlarda yeterli perikonsepsiyonel FA alım oranı daha yüksek tespit edilmiştir. ${ }^{6,27}$ Bizim çalışmamızda da benzer fark mevcuttur. Buna rağmen, gebelik öncesi bakım alanlarda dahi konsepsiyon öncesi FA alım oranın \%30'larda kalması gebelik öncesi bakımın niceliksel azlığının yanında niteliksel olarak da yetersiz kaldığını göstermektedir. 2009'da Turgul ve arkadaşları düzenlendikleri bir kampanya ile kadınlar arasında FA hakkında bilgi düzeyinin arttığını bildirmiştir. ${ }^{28}$ Benzer kampanyaların yapılması bilgi düzeyinin yükselmesi ve FA'nın doğru kullanımını artabilir.

2014 de yayınlanan bir derlemede; perikonsepsiyonel sigara maruziyetinin konjenital kalp hastalıkları riskini 3 kat arttırdığı ifade edilmiştir. ${ }^{18}$ Bundan dolayı konsepsiyon öncesi ve 
sonrası sigara maruziyetinin ortadan kaldırılması gebelik öncesi bakım planında büyük öneme sahiptir. Ancak çalışmamızda gebeliği süresince sigara kullanmaya devam edenlerin oranı düşük olsa da $(\% 6,5)$, plansız gebeliklerde gebelik anlaşılana kadar geçen sürede sigara kullanımı devam etmiştir. Yine her üç gebeden birinin, sigara dumanına maruz kaldığı görülmüştür. Gebelik öncesi danışmanlık almanın da bu duruma etkisi olmamış ve bir diğer açıdan gebelik öncesi bakım hizmetinin yetersizliği ortaya çıkmıştır.

Çalışmamızın kısıtlılığı, üçüncü basamak bir sağlık kuruluşunda ve gebeler üzerinde yürütülmüş olmasıdır. Bu durum sonuçların toplumu yansitmasına engel olmaktadır.

\section{SONUÇ}

Ülkemizde, doğum öncesi bakım hizmetleri açısından önemli adımlar atılmış ancak gebelik öncesi bakım konusuna yeterince değinilmemiştir. ${ }^{29}$ Bizim çalışmamızda bunu destekleyici niteliktedir. Gebelik öncesi bakım hizmetlerinin, kadın ve olası çocuklarının sağlığının geliştirilmesi açısından önemi açıktır. Bu kapsamda, doğru FA kullanımı ve sigara maruziyetinin önlenmesine özellikle dikkat edilmelidir. Birinci basamakta aile hekimi ve aile sağlığı elemanlarının, gebelik öncesi bakım hizmetleri açısından 15-49 yaş evli kadın izlemlerine daha fazla ağırlı vermeleri gerektiği görünmektedir.

\section{KAYNAKLAR}

1. Temel S, van Voorst SF, de Jong-Potjer LC, Waelput AJ, Cornel MC, de Weerd SR, et al. The Dutch national summit on preconception care: a summary of definitions, evidence and recommendations. Journal of community genetics. 2015;6(1):107-115.

2. Dickinson JE. Preconception assessment: An opportunity often lost. Australian and New Zealand Journal of Obstetrics and Gynaecology. 2014;54(6):501-2.

3. Johnson K, Posner SF, Biermann J, Cordero JF, Atrash HK, Parker CS, et al. Recommendations to improve preconception health and health care--United States. A report of the CDC/ATSDR Preconception Care Work Group and the Select Panel on Preconception Care. MMWR Recomm Rep. 2006;55(RR-6):1-23.

4. Williams L, Zapata LB, D'Angelo DV, Harrison L, Morrow B. Associations between preconception counseling and maternal behaviors before and during pregnancy. Maternal and child health journal. 2012;16(9):1854-61.

5. Oza-Frank R, Gilson E, Keim SA, Lynch CD, Klebanoff MA. Trends and Factors Associated with Self-Reported Receipt of Preconception
Care: PRAMS, 2004-2010. Birth. 2014;41(4):367-73.

6. Beckmann MM, Widmer T, Bolton E. Does preconception care work? Aust N Z J Obstet Gynaecol. 2014;54(6):510-4.

7. Shawe J, Delbaere I, Ekstrand M, Hegaard HK, Larsson M, Mastroiacovo $\mathrm{P}$, et al. Preconception care policy, guidelines, recommendations and services across six European countries: Belgium (Flanders), Denmark, Italy, the Netherlands, Sweden and the United Kingdom. The European Journal of Contraception \& Reproductive Health Care. 2015;20(2):77-87.

8. Şahin M, Yurdakul M. Gebelik öncesi danışmanlık. Florence Nightingale Hemşirelik Dergisi. 2012;20(1):80-5.

9. Moos MK, Dunlop AL, Jack BW, Nelson L, Coonrod DV, Long R, et al. Healthier women, healthier reproductive outcomes: recommendations for the routine care of all women of reproductive age. Am J Obstet Gynecol. 2008;199(6 Suppl 2):S280-9.

10. Shores SE, Bailey T. Recommendations for women of reproductive age. N C Med J. 2009;70(5):432-8.

11. Mook-Kanamori DO, Steegers EA, Eilers PH, Raat H, Hofman A, Jaddoe VW. Risk factors and outcomes associated with first-trimester fetal growth restriction. JAMA. 2010;303(6):527-34.

12. van der Zee B, de Beaufort I, Temel S, de Wert G, Denktas S, Steegers E. Preconception care: an essential preventive strategy to improve children's and women's health. J Public Health Policy. 2011;32(3):367-79.

13. Wilkes J. AAFP releases position paper on preconception care. American family physician. 2016;94(6):508.

14. Callegari LS, Ma EW, Schwarz EB. Preconception care and reproductive planning in primary care. Medical Clinics of North America. 2015;99(3):663-82.

15. Lu MC, Kotelchuck M, Culhane JF, Hobel CJ, Klerman LV, Thorp JM. Preconception care between pregnancies: the content of internatal care. Maternal and Child Health Journal. 2006;10(1):107-22.

16. Gavin L, Moskosky S, Carter M, Curtis K, Glass E, Godfrey E, et al. Providing quality family planning services: Recommendations of CDC and the U.S. Office of Population Affairs. MMWR Recomm Rep. 2014;63(RR-04):1-54.

17. Wolff T, Witkop CT, Miller T, Syed SB. Folic acid supplementation for the prevention of neural tube defects: an update of the evidence for the US Preventive Services Task Force. Annals of Internal Medicine. 2009;150(9):6329. 
18. Lassi ZS, Imam AM, Dean SV, Bhutta ZA. Preconception care: caffeine, smoking, alcohol, drugs and other environmental chemical/radiation exposure. Reproductive health. 2014;11(3):1.

19. Öztaş Ö, Artantaş AB, Tetik BK, Yalçıntaş A, Üstü Y, Uğurlu M. 18-49 yaş grubu evli kadınların üreme sağlığı ve kontrasepsiyon hakkındaki bilgi, tutum ve davranışları. Ankara Med J. 2015; 15(2):67-76.

20. Hacettepe Üniversitesi Nüfus Etütleri Enstitüsü (2014), "2013 Türkiye Nüfus ve Sağlık Araştırması". Hacettepe Üniversitesi Nüfus Etütleri Enstitüsü, T.C. Kalkınma Bakanlığı ve TÜBİTAK, Ankara, Türkiye.

21. Finer LB, Zolna MR. Declines in unintended pregnancy in the United States, 2008-2011. N Engl J Med. 2016;374(9):843-52.

22. Finer LB, Zolna MR. Shifts in intended and unintended pregnancies in the United States, 2001-2008. Am J Public Health. 2014;104 Suppl 1:S43-8.

23. Tezel A, Gönenç İ, Akgün Ş, Öztaş Karataş D, Altuntaş Yıldız T. Kadınların aile planlamasına yönelik tutumları ve etkileyen faktörler. Journal of Anatolia Nursing and Health Sciences. 2015;18(3):181-188.

24. Gözükara F, Kabalcıoğlu F, Ersin F. Şanlıurfa İlinde Kadınların aile planlamasına ilişkin tutumlarının belirlenmesi. Harran Üniversitesi Tıp Fakültesi Dergisi. 2015;12(1):9-16

25. Köken GN, Derbent AU, Erol O, Saygın N, Ayık H, Karaca M. Awareness and use of folic acid among reproductive age and pregnant women. Journal of the Turkish German Gynecological Association. 2013;14(2):87.

26. Baykan Z, Öztürk A, Poyrazoğlu S, Gün İ. Awareness, knowledge, and use of folic acid among women: a study from Turkey. Archives of gynecology and obstetrics. 2011;283(6):1249-53.

27. Elsinga J, de Jong-Potjer LC, van der Pal-de KM, le Cessie S, Assendelft WJ, Buitendijk SE. The effect of preconception counselling on lifestyle and other behaviour before and during pregnancy. Women's Health Issues. 2008;18(6):S117-S25.

28. Turgul O, Anli N, Mandiracioglu A, Bati H, Akkol S. The regional campaign for women on awareness of neural tube defects and folic acid in Narlidere, Izmir: a community-based intervention. Eur J Contracept Reprod Health Care. 2009;14(1):69-74.

29. Baysoy NG, Özkan S. Gebelik öncesi (prekonsepsiyonel) bakım: Halk sağlığ1 perspektifi. Gazi Medical Journal. 2012;23(3):77-90 